\begin{abstract}
Developing the Parachute System for NASA’s Orion - An Overview at Inception

Ricardo Machin

Johnson Space Center

NASA Johnson Space Center

Anthony P. (Tony) Taylor

Robert Sinclair

Irvin Aerospace Inc

Paul Royall

Jacobs Sverdrup

As the Crew Exploration Vehicle (CEV) program developed, NASA decided to provide the parachute portion of the landing system as Government Furnished Equipment (GFE) and designated NASA Johnson Space Center (JSC) as the responsible NASA center based on JSC's past experience with the X-38 program. JSC subsequently chose to have the Engineering Support contractor Jacobs Sverdrup to manage the overall program development.

After a detailed source selection process Jacobs chose Irvin Aerospace Inc (Irvin) to provide the parachutes and mortars for the CEV Parachute Assembly System (CPAS). Thus the CPAS development team, including JSC, Jacobs and Irvin has been formed.

While development flight testing will have just begun at the time this paper is submitted, a number of significant design decisions relative to the architecture for the manned spacecraft will have been completed. This paper will present an overview of the approach CPAS is taking to providing the parachute system for CEV, including: system requirements, the preliminary design solution, and the planned/completed flight testing.
\end{abstract}




\title{
Developing the Parachute System for NASA's Orion - An Overview at Inception
}

\author{
Anthony P. (Tony) Taylor, Director Space Systems \\ Robert Sinclair, CPAS Chief Engineer \\ Irvin Aerospace Inc
Ricardo Machin, CPAS Subsystem Manager
NASA Johnson Space Center

\section{Paul Royall, CPAS Deputy Program Manager \\ Jacobs Sverdrup}

\begin{abstract}
The CEV is an element of the Constellation Program that includes launch vehicles, spacecraft, and ground systems needed to embark on a robust space exploration program. As an anchoring capability of the Constellation Program, the CEV shall be human-rated and will carry human crews and cargo from Earth into space and back again. Coupled with transfer stages, landing vehicles, and surface exploration systems, the CEV will serve as an essential component of the architecture that supports human voyages to the Moon and beyond. In addition, the CEV will be modified, as required, to support International Space Station (ISS) mission requirements for crewed and pressurized cargo configurations.

As the Crew Exploration Vehicle (CEV) program developed, NASA decided to provide the parachute portion of the landing system as Government Furnished Equipment (GFE) and designated NASA Johnson Space Center (JSC) as the responsible NASA center based on JSC's past experience with the X-38 and other parachute programs. JSC subsequently chose to have the engineering support contractor Jacobs
\end{abstract}

Engineering to manage the overall program development.

After a detailed source selection process Jacobs selected Irvin Aerospace Inc (Irvin) to provide the parachutes and mortars for the CEV Parachute Assembly System (CPAS). The parachute mortars are being design for Irvin under subcontract by General Dynamics - Ordinance and Technical Devices (GD-OTS). Thus the CPAS development team, including JSC, Jacobs, Irvin and GD-DOTS has been formed.

While development flight testing will have just begun at the time this paper is submitted, a number of significant decisions relative to the future of manned spacecraft will have been completed. This paper will present an overview of the approach CPAS is taking to providing the parachute system for the CEV including: a review of the overall system requirements, the preliminary design solution, and planned and completed development flight tests.

\section{System Requirements}


Parachutes will be used as the primary landing system for the CEV for normal and abort landings on Earth. Nominal landings will be on land; whereas, abort landings could be on land or water. One parachute system design is required to fit the requirements for all CEV variants. The shape of the Command Module (CM) is based upon the Apollo capsule with a vehicle weight of 17,176 lbs behind a 5 meter heat shield at the time that the parachute recovery system is initiated. As the parachute recovery system is going to be required for early prototype testing of the CEV launch abort system (specifically the Pad Abort test \#1 or PA-1), the development of the CPAS has been broken into two phases.

A Generation 1 system, based on preliminary requirements drawn from the NASA generated CEV architecture and mission profile prior to selecting Lockheed Martin as the CEV prime contractor, will demonstrate the basic system end to end with all the components integrated into a boiler plate type test article. The Generation 2 design that will allow for the CEV program requirements to mature and be the design that is taken into the qualification testing for human rating. The hope at the inception of the recovery system project is that the final CEV requirements will not cause the Generation 2 design to depart radically from Generation 1 . The CPAS project is currently responsible for supporting the seven planned ascent abort tests (some of which will be incorporated into the human rating qualification tests) up through the first three human flights.

There are a total of six bays at the top of the $\mathrm{CEV}$, above the pressurized compartment bulkhead and wrapping around the transfer tunnel (see Figure 1). The CPAS shall be stowed within the torus volume created by the transfer tunnel, upper bulkhead, and the Outer Mold Line (OML) of the vehicle (including the Micro-Meteorite and Orbital Debris protection system). The CPAS shall not exceed 1,200 lbs in total weight, to include the parachutes, the risers and harness and the mortars. The CPAS mains will be allocated $25.57 \mathrm{ft} 3$ of volume with the intent of not exceeding $35 \mathrm{lb} / \mathrm{ft} 3$ average packing density. The CPAS shall be capable of sustaining a single parachute failure in either the drogues or mains and still function safely recovering the crew.

The CPAS will be deployed in subsonic controlled flight with the angle of attack and sideslip within 40 degrees of trim, the vehicle pitch and yaw rates less than $40 \mathrm{deg} / \mathrm{sec}$ and the vehicle roll rate less than $80 \mathrm{deg} / \mathrm{sec}$. The CPAS will be initiated at altitudes ranging from 4,000 to $40,000 \mathrm{ft}$ AGL. The vehicle weight at drogue deploy is assumed to be 17,176 lbs. The drogues will be deployed at dynamic pressures ranging from 19 to $115 \mathrm{psf}$ and be required to stabilize and decelerate the vehicle prior to release and deployment of the mains. The vehicle weight at touchdown is assumed to be 14,400 lbs. The CPAS shall nominally deliver no greater than 26 $\mathrm{ft} / \mathrm{sec}$ rate of descent and no greater than $33 \mathrm{ft} / \mathrm{sec}$ with one main failed using an air density of 0.00182526 (representing a three sigma dispersed hot day at White Sands Missile Range). The CPAS shall stabilize the vehicle to within $+/-5$ degrees of the desired hang angle, recognizing that the hang angle for land and water landings will likely be different. 
The CPAS shall be two fault tolerant for catastrophic hazards and single fault tolerant for critical hazards, with the exception of elements approved to use Design for Minimum Risk criteria (such as confluence fittings). The CPAS shall be capable of withstanding any single parachute skipping stage during deployment and still function properly. The CPAS shall not transfer greater than $5 \mathrm{~g}$ 's of load into the vehicle with the goal of not exceeding 3 g's. All pyrotechnic elements of CPAS shall comply with the Human Rated Spacecraft Pyrotechnic Specification JSC 62809. The load bearing elements of the CPAS shall be designed with a minimum factor of safety of 1.6 , with a factor of 2.0 used on critical elements (such as reefing) and items not verified by testing. The CPAS components will not be exposed to temperatures greater than 180 deg F. The CPAS components shall be spaceflight and vacuum compatible with expected mission durations of up to 180 days.

\section{Preliminary System Solution}

At present the winning CPAS proposal with no major change has been adopted as the Generation 1 design. This point of departure includes a large return to the legacy of the Apollo program recovery system with some updates in parachute architecture that recognize that $\mathrm{CEV}$ is required to support a land landing.

Similarities between the CPAS configuration and the Apollo legacy include:

1) Dual Drogue Configuration Either Parachute is sufficient and both are deployed simultaneously
2) Three Main Parachute Configuration - All are deployed simultaneously and any 2 are sufficient for safe landing

3) Use of Pilot Parachutes to deploy each main parachute individually - The geometry of the top of the CEV spacecraft, much like Apollo, makes this the preferred deployment technique

4) Heritage; the parachute designs and deployment methods are largely the same as Apollo
a. Mortar Deployed Drogue Parachutes
b. Mortar Deployed Pilot Parachutes
c. Pilot Deployed Main Parachutes
d. Ringsail Main
Parachutes

Differences between that Apollo and CPAS configurations include the following:

1) The use of modern materials - Kevlar, Vectran and Spectra did not exist in the Apollo era, most have current spaceflight heritage and all have significant parachute system heritage

2) Drogue Parachutes are updated to a Variable Porosity Conical Ribbon (VPRC) Parachute - This approach captures NASA and Irvin's experience in the development of the Space Shuttle Drag Chute and the thousands and thousands of deployments of the F-16 
Landing Parabrake, which uses the same technology.

3) The Main Parachute design is updated from Ringsail technology of the 1960s to the Irvin Quarter-spherical technology described in previous papers and is presented as Reference 1.

Figure 2 provides a schematic sequence of the nominal CPAS deployment sequence. Two drogue parachutes are deployed at an altitude consistent with safely deploying the mains (allowing for optimization of the touchdown footprint) and a sub-sonic Mach number. The drogue parachutes are Variable Porosity Conical Ribbon (VPCR) Parachutes that take their design heritage from the Shuttle Drag Chute and the F-16 Landing Brake. Both the Shuttle and F16 designs have been proven to have excellent flight stability and high reliability during deployment and inflation. Figure 3 provides a view of the Shuttle and F-16 Parachutes in flight.

While the drogue parachute system assumes that one drogue parachute is required to deliver the CEV to the main parachute deployment conditions both are deployed simultaneously to simplify the control and deployment logic. In the event that no drogues deploy, preliminary loads and stress analysis indicates that the main parachutes could still safely inflate and function properly, this CPAS capability (once confirmed in development testing) will afford an enhanced level of crew survivability.
The Main parachute system is based on the legacy of the early US Manned Space Flight program, namely, Mercury, Gemini, and Apollo which all used Ringsail parachutes in various configurations. We do not intent to review permutations between these programs here, but the fact that All US Manned Spacecraft with parachute landing systems have chosen the Ringsail for the main parachute is a strong indication of its suitability.

In the past 2 plus decades the Ringsail technology has been further enhanced by Irvin during a number of development programs related to large Ringsail construction and flight testing including the F-111 Crew Escape Module Enhancement Program, the Boeing Enhanced Expendable Launch Vehicle, and the Kistler K-1 Landing System Development.

Figure 4 left 2 images provides some images of flight test experience with the 85.6 Ringsail design that has led to some of the follow on programs. This configuration comes from the F-111 CEM upgrade program in the late 1980's and has led directly to the design presented below. Figure 5 provides an illustration of some of the Irvin designed Ringsail systems that have directly lead to the design adopted for the Generation 1 mains. The most left figure is a cluster of three136 ft Ringsail parachutes developed for the Boeing EELV Program. The middle image and Figure 6 is a test of a cluster of three $156 \mathrm{ft}$ diameter Kistler design mains. All parachutes have the same design heritage and legacy and provide a huge 
flight test experience to support the CPAS parachute development.

The CPAS Generation-1 main parachutes are $116 \mathrm{ft}$ diameter and this is sized by a number of constraints that continue to be refined. However, it can be said with great certainty that the final CPAS diameter requirement will be between the range of 85 and 156 feet already demonstrated on prior programs.

The Irvin Quarter spherical construction is demonstrated in Figure 7, illustrating that the parachute is constructed as the top $1 / 4$ of a sphere. The fabric permeability and geometric porosity from the crown to the skirt has been tailored to provide a highly efficient (high drag to parachute weight) canopy, providing stable flight mode in clusters, and controlled and measured inflation characteristics.

In general 3 zones are established with low permeability in the crown zone, intermediate in the shoulder region and standard permeability in the skirt region. The overall fabric strength has been tailored for the predicted loads and varies throughout the zones. These features lead to a design that is both robust and forgiving during various flight phases. An important feature that this design has demonstrated in past applications is that it can be reefed to much smaller first stage drag areas than other designs (flat circular, extend skirt, etc) with the lower panel sails, which are used as parachute outlets in full inflation, acting as inlets during initial parachute inflation. This feature, along with the distribution of ribbon strength in the canopy, provides the ability to meet the skipped stage requirement.
Figure 8 provides images of parachute Sails behaving in alternate modes (inlet or outlet).

\section{Program Plan and Testing to Date}

At the time of this writing flight testing of the CPAS parachutes has begun. To date, 4 flight tests have been completed of the pilot parachute in a single parachute flight test mode. These have been accomplished with small Cylindrical Test Vehicles (CTV) with a weight of about $550 \mathrm{lb}$. The Generation1 Main Parachute pack is predicted to weigh approximately 250 lbs, thus these flight tests establish flight performance with some margin. Figures 9 and 10 provide some images from these flight tests.

In the spring of 2007 testing will begin of the drogue parachute - in a single parachute mode - of the CPAS Generation 1 design. The first several tests (1-4) will explore the operational envelope of the parachute, such as low speed (pad abort) to high speed (ascent abort). Following that, two cluster drogue flight mode and mortar deployment during flight are planned. Figure 11 provides a photo of the first 23 ft CPAS drogue parachute.

Main Parachute construction has begun for the Generation-1 $116 \mathrm{ft}$ Ringsail. Flight testing begins in the late summer of 2007 and progresses through a number of flights that will be completed bounding the anticipated deployment and wing loading conditions for the CEV. The Generation-1 CPAS design has a major milestone to support the Pad Abort -1 (PA-1) Flight Test currently scheduled for September of 2008, this has placed specific Gen-1 development 
tests of cluster deployments from capsule shape on the critical path to meeting the PA-1 CPAS delivery. As a result the development testing schedule has been shuffled to meet this delivery requirement; however the main parachute flight test program will not change in terms of content. Figure 12 provides an image of the Parachute Test Vehicle (PTV) or boilerplate, that is being designed and manufactured at JSC which will be used to complete these tests, leading to the PA-1 Flight Test. The PTV will have the correct geometry for the CPAS installation and be capable of being mounted to a standard weight tub or to a full scale heat shield. The total height of the PTV in the heat shield configuration will be approximately 24 inches shorter than the CEV. Figure 13 provides a dimensional side view comparison of the PTV to the CEV.

Mortar development testing has been begun as well. To date, closed bomb tests of the mortar gas generator have been completed for the pilot parachutes. Closed bomb testing for the drogues and dummy parachute pack shots are scheduled to take place for both the pilot and drogue mortars by May '07. Static mortar firings with complete parachute assemblies will be completed in spring of ' 07 followed by flight tests in the fall of '07 that include mortar deployed parachutes. Figure 14 provides an illustration of the parachute mortars as they are currently integrated into the CEV upper compartment.

\section{Summary}

In many ways the CPAS effort is ahead of the overall CEV effort and thus serves as a pathfinder to define system requirements related to integration with the overall landing system as well as the vehicle structure. The difficult work of packaging the system and demonstrating that it can be safely deployed remains, however the design is progressing, the hardware is being manufactured and the testing has begun. The limited testing to date has been successful generating data that indicates that the pilot parachutes will support the Pad Abort Test \#1 predicted flight conditions.

Much continues to evolve in the CEV development and the CPAS team continues to evolve with the overall program. However, to date, the CPAS design and testing progresses and will be ready to meet the mission of Constellation; to the Moon, Mars and beyond!

\section{References:}

1) Delurgio, Philip R., "The Evolution of the Ringsail” AIAA Paper \# 99-1700, AIAA $15^{\text {th }}$ ADS Conference, June 8-11 1999. 


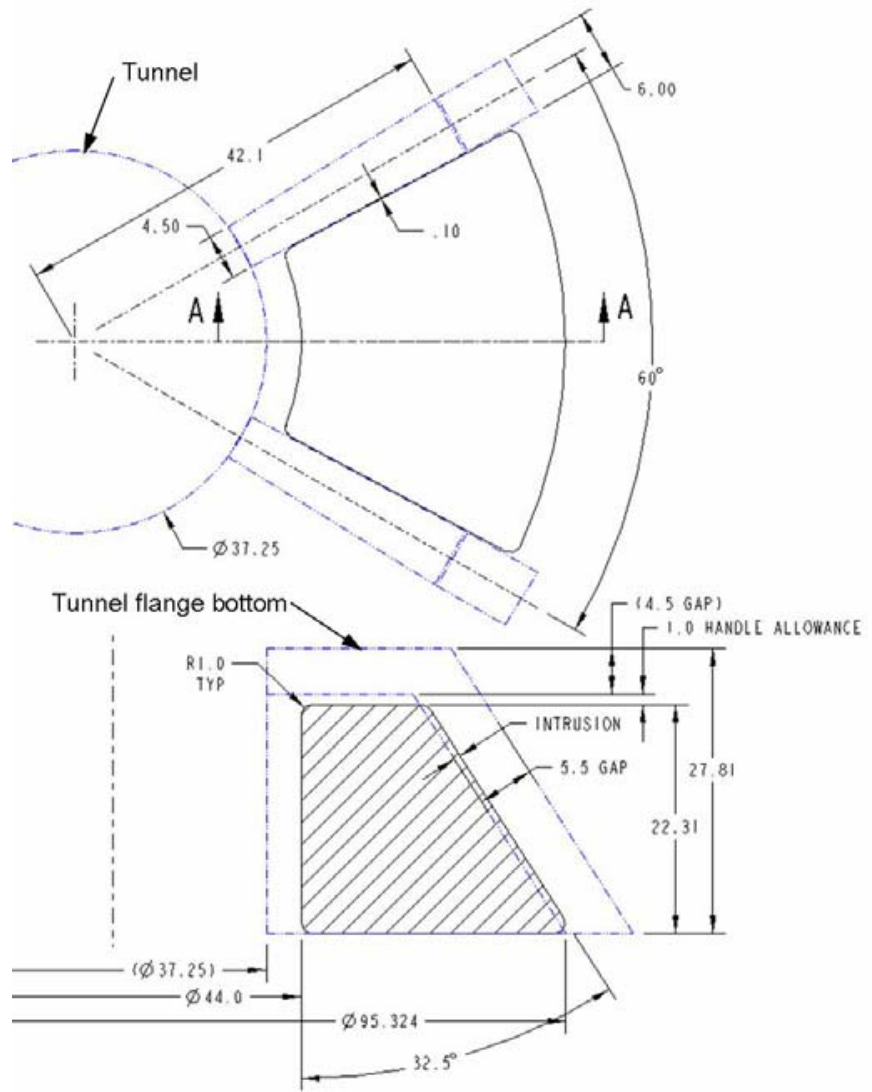

Figure 1 - Illustration of the Top of the CEV Spacecraft 


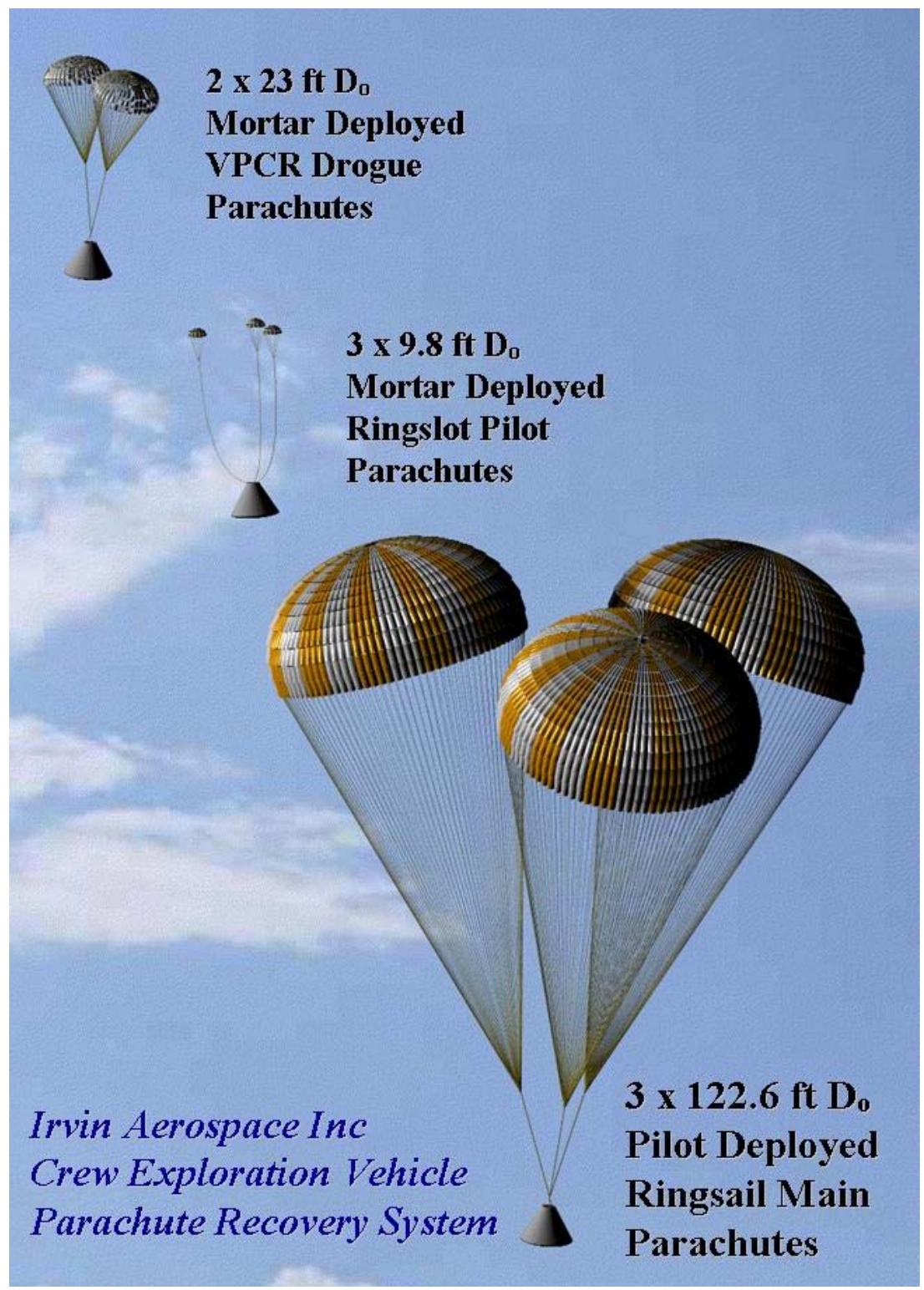

Figure 2 - Recovery Sequence 

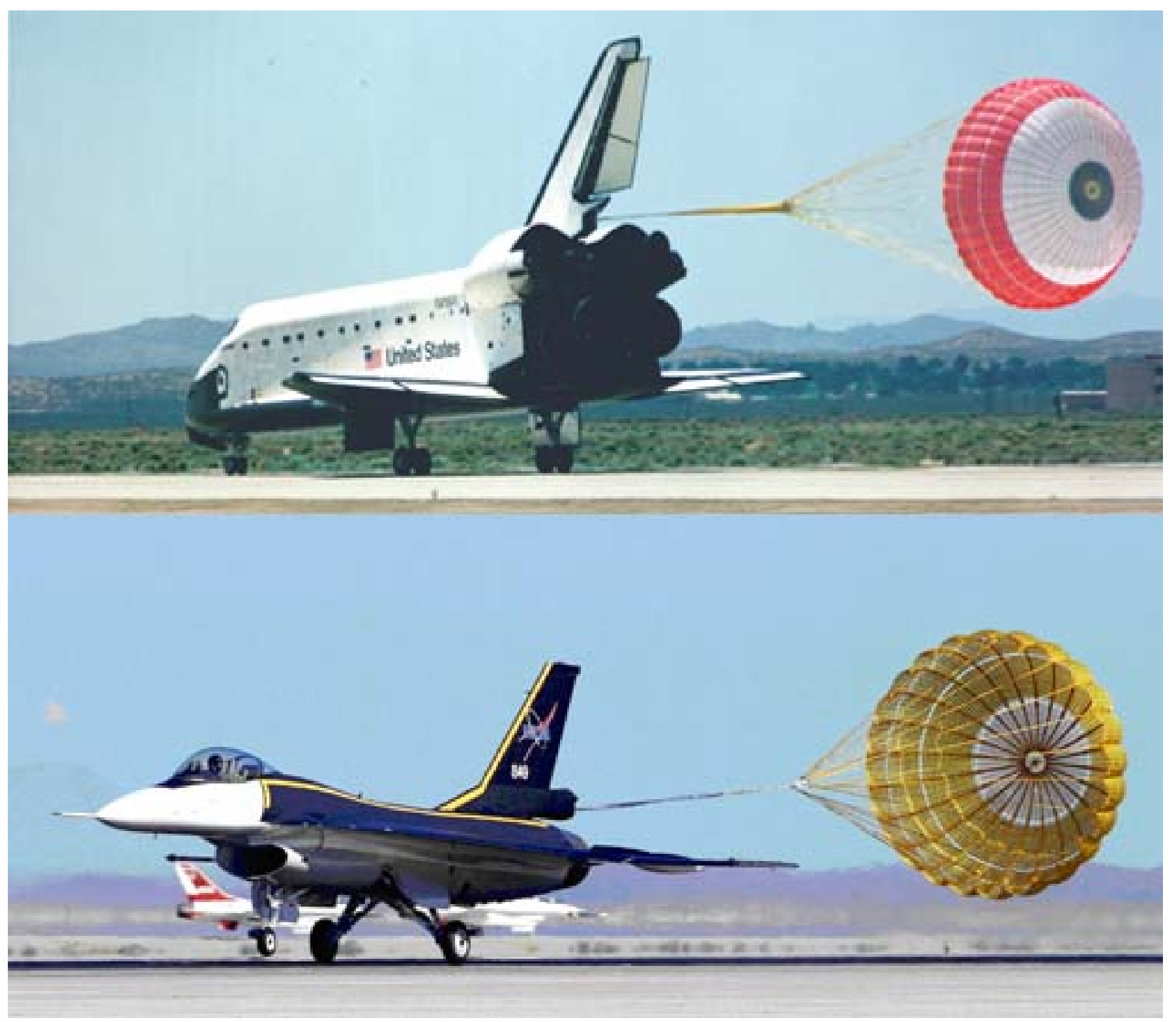

Figure 3 - Drogue Parachute Legacy 


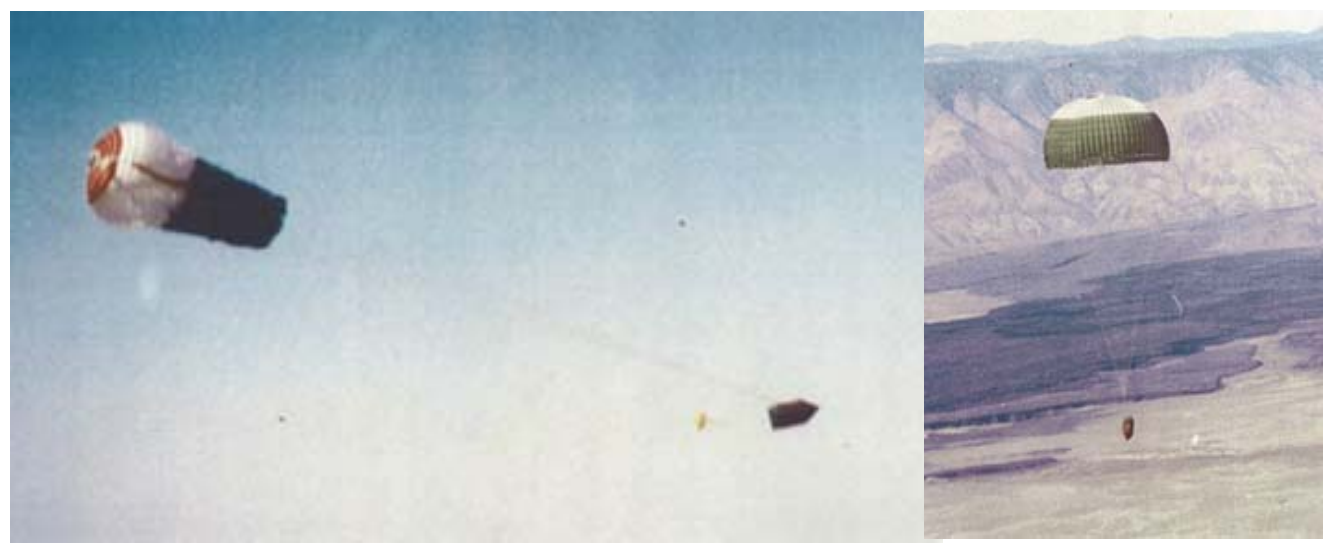

Figure 4 - Main Parachute Legacy

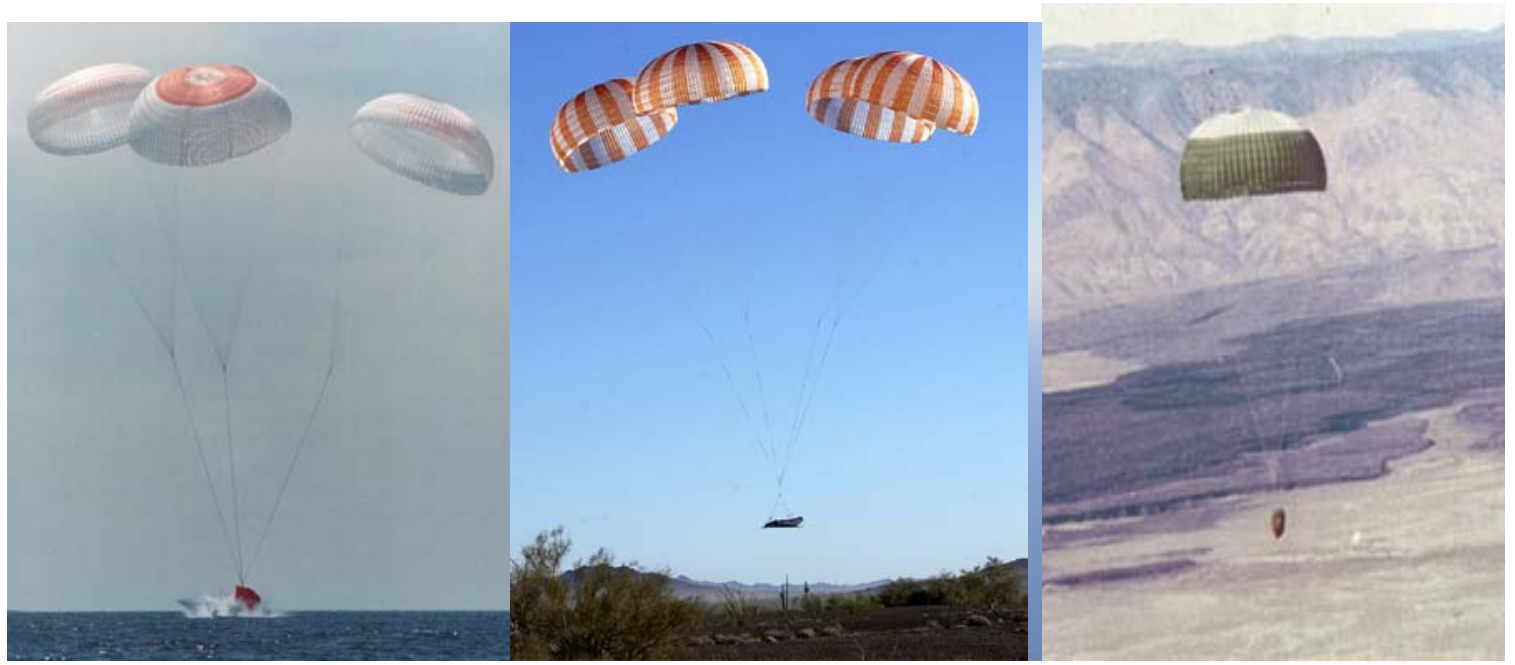

Figure 5 - Main Parachute heritage 


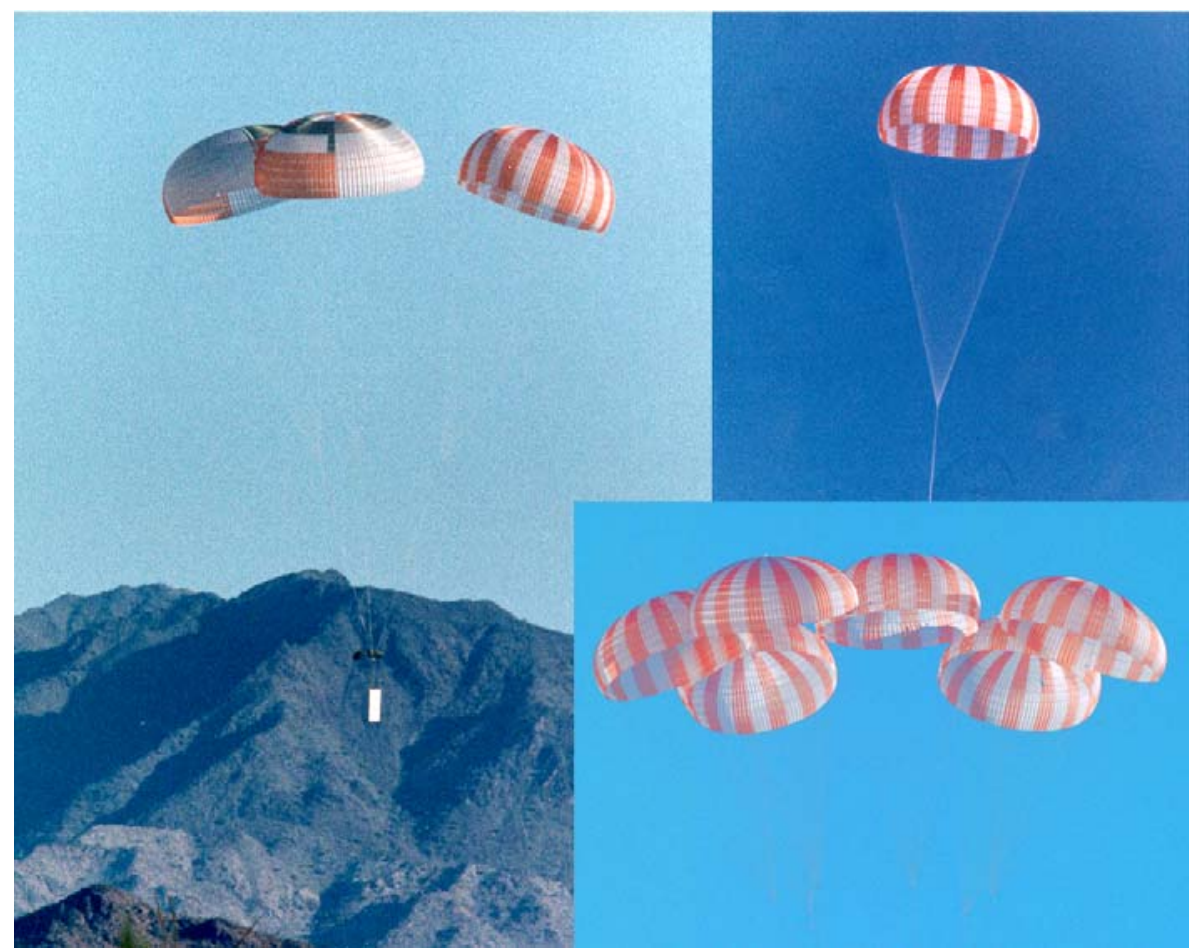

Figure 6 - Images of Kistler Main Parachute Flight Tests

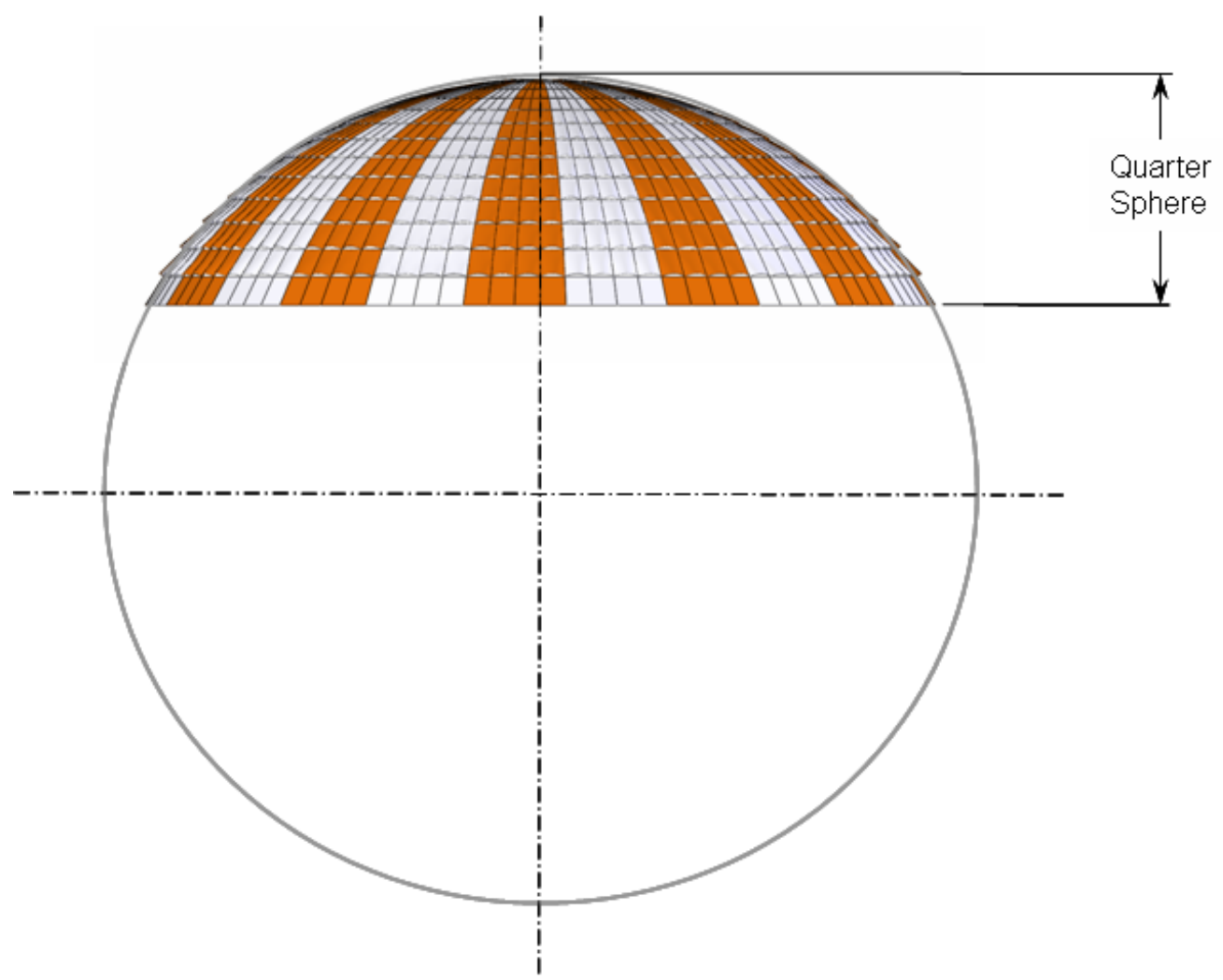

Figure 7 - Parachute Construction Technology 


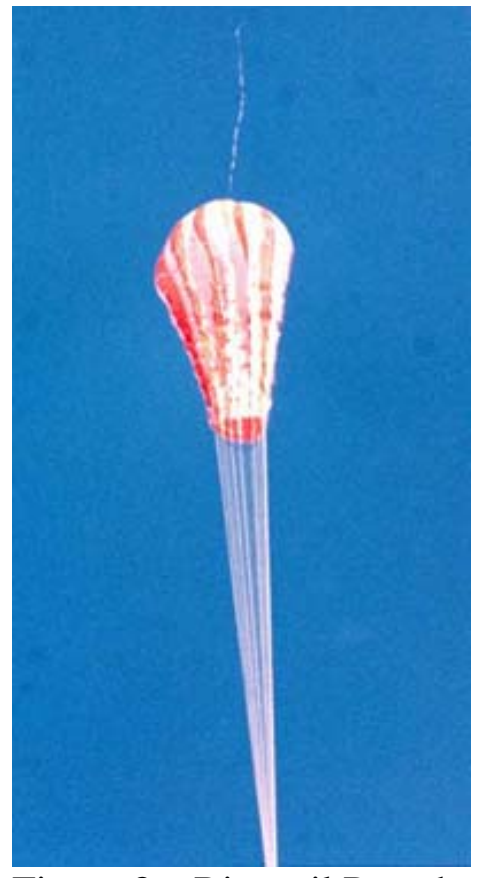

Figure 8 - Ringsail Parachute with Sail as Inlets and Outlets

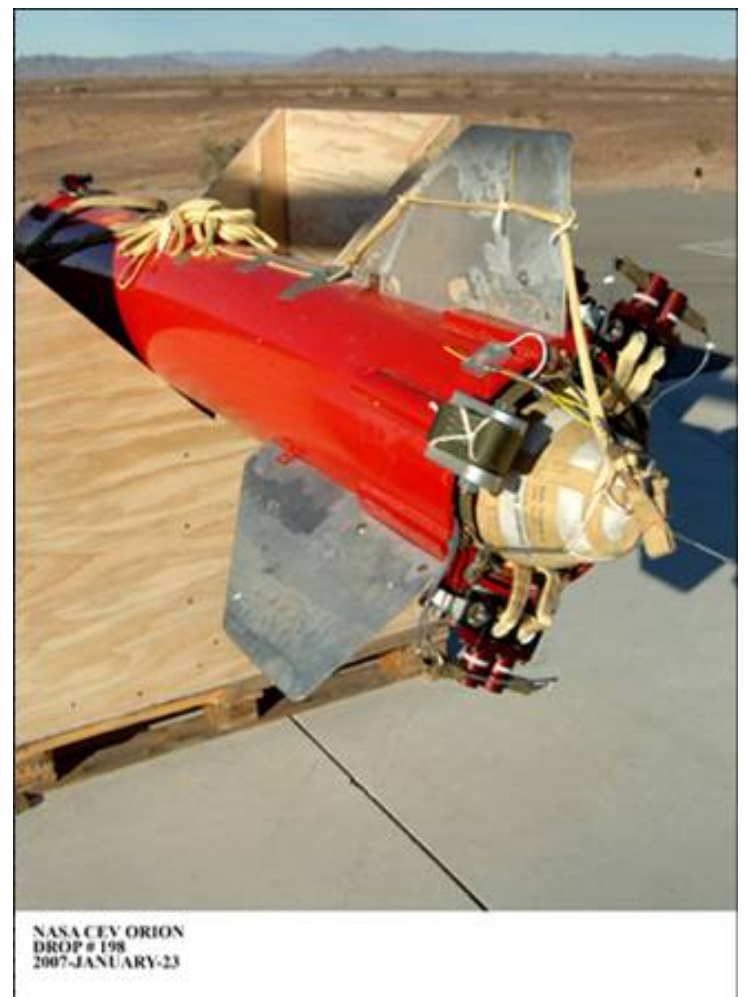

Figure 9 - Pilot Parachute Drop Text Vehicle 


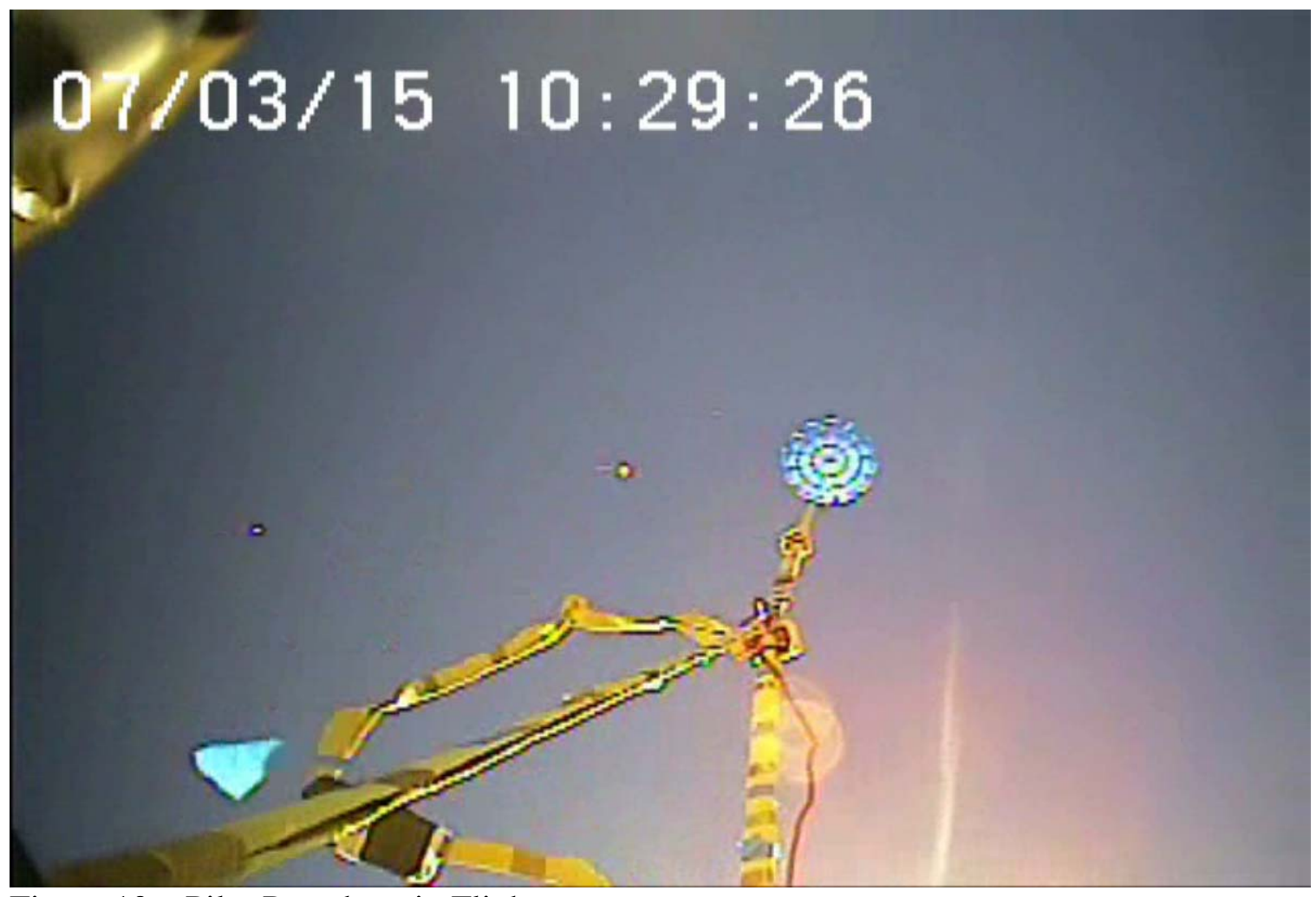

Figure 10 - Pilot Parachute in Flight

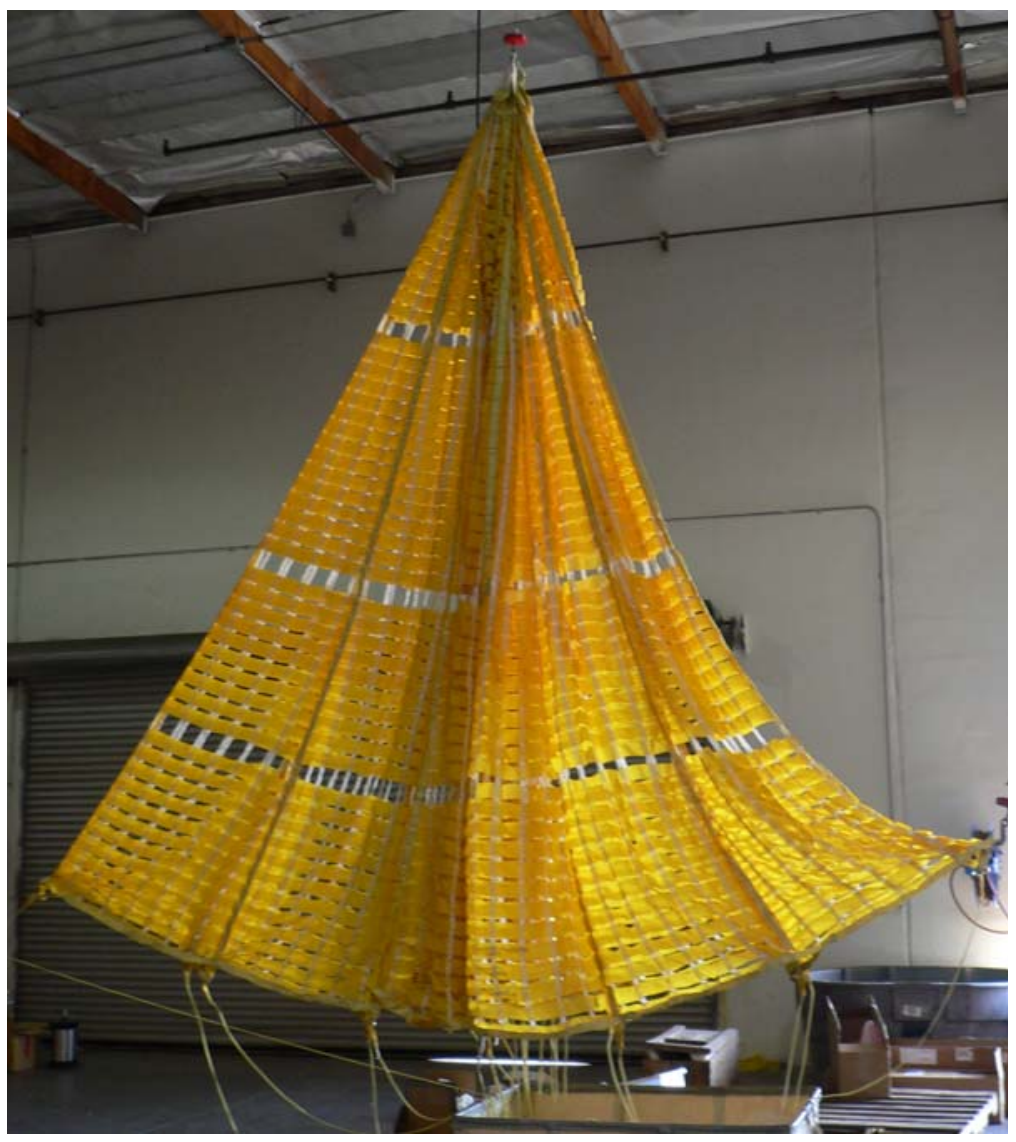


Figure 11 - Completed CPAS Drogue Parachute
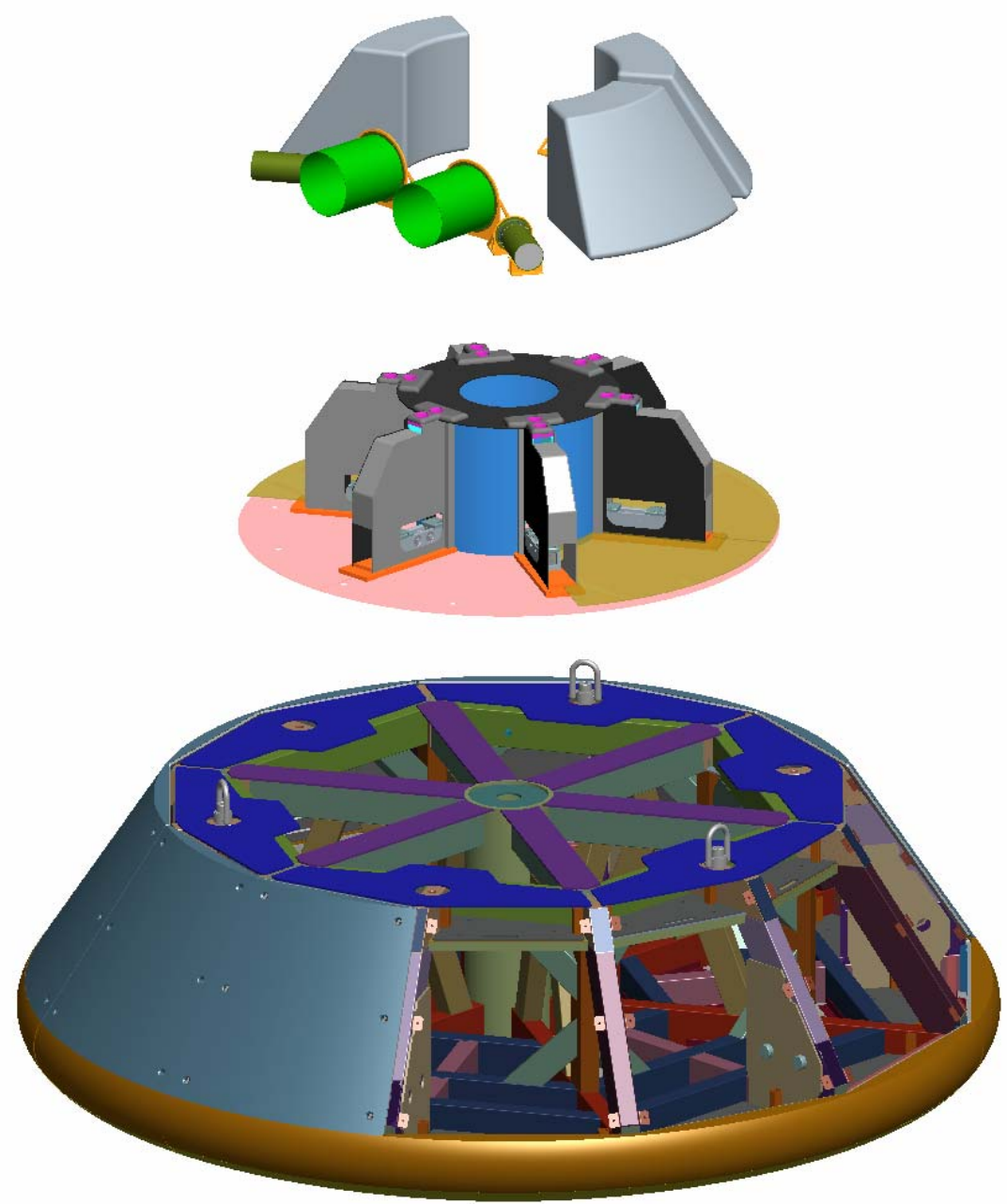

Figure 12 - View of the top of the Parachute Test Vehicle

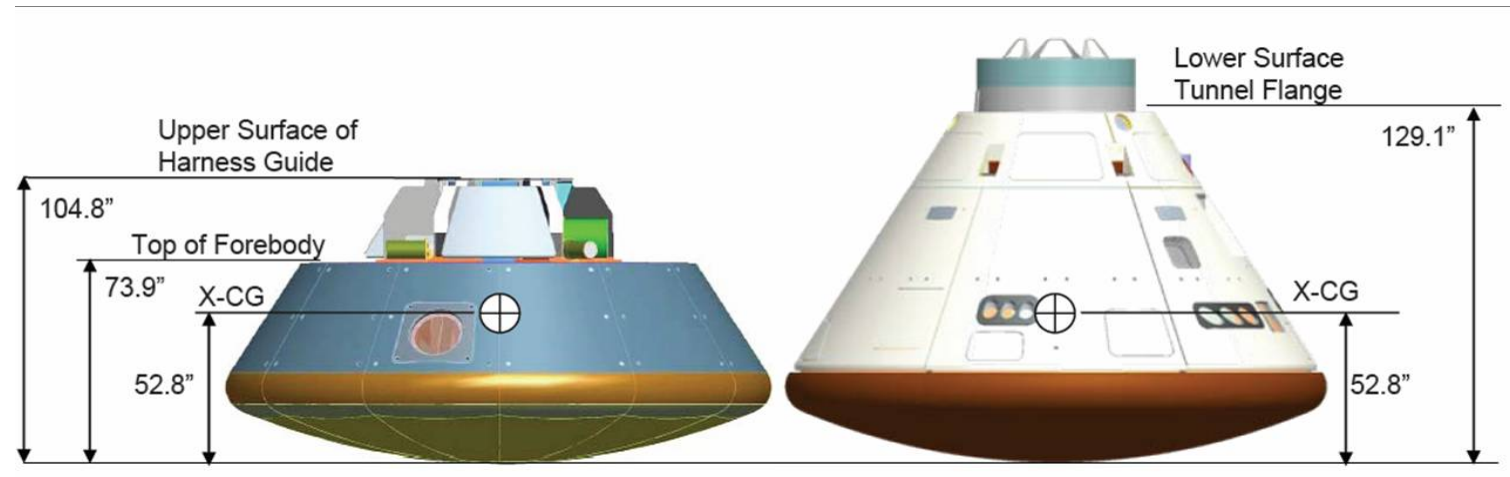

Figure 13 - Comparison of Parachute Test Vehicle and Full Orion Capsule 


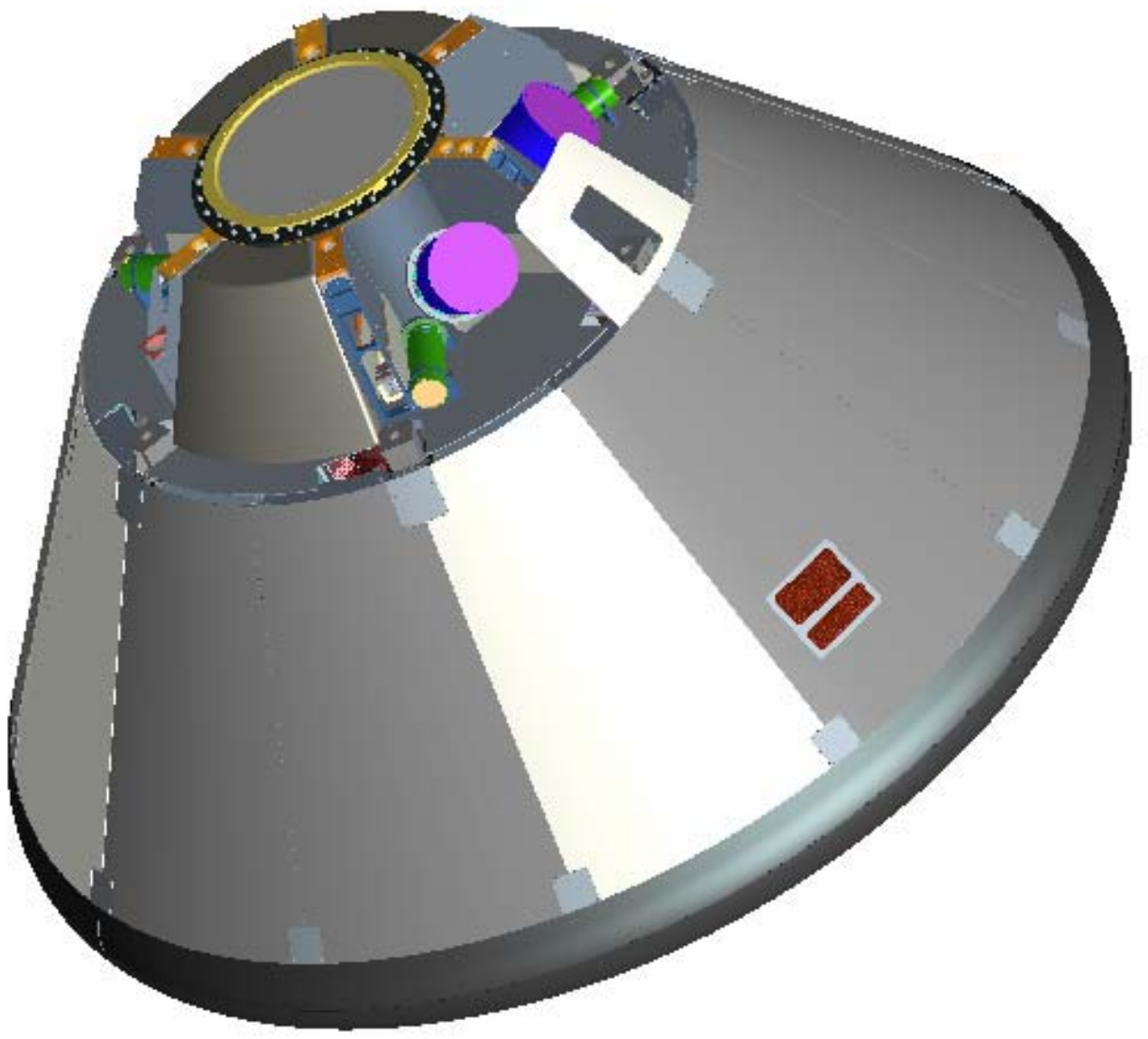

Figure 14 - Detail View of Parachutes and Mortars in Top of Spacecraft 